\title{
METABOLISM OF 7-H'B-EPINEPHRINE-d-BITARTRATE IN NORMAL YOUNG MEN
}

\author{
By ELWOOD H. LABROSSE, JULIUS AXELROD, IRWIN J. KOPIN AND \\ SEYMOUR S. KETY
}

\author{
(From the Laboratory of Clinical Science, National Institute of Mental Health, National In- \\ stitutes of Health, Bethesda, Md.)
}

(Submitted for publication August 25, 1960 ; accepted September 30, 1960)

\begin{abstract}
Because of the numerous and important physiological and biochemical actions of epinephrine, the inactivation and metabolism of this and other catechol amines have been the subject of considerable interest, especially in recent years. In 1951 Schayer demonstrated in the urine of rats the presence of four metabolic products of injected $\mathrm{C}^{14}$-epinephrine, but these remained unidentified (1). As recently as 1957 the major pathways and products of catechol amine metabolism were unknown, although it was assumed that the primary route of disposition was mainly by way of oxidative deamination $(2,3)$.
\end{abstract}

In 1957 Armstrong, McMillan and Shaw identified 3-methoxy-4-hydroxymandelic acid as a major metabolite of epinephrine and norepinephrine (4). Considering the possible routes of metabolism of the catechol amines in the light of this report, Axelrod sought and demonstrated a new pathway of epinephrine metabolism by 3-Omethylation (5). He showed that 3-O-methyl epinephrine (metanephrine) was formed in vitro when a nonparticulate fraction of rat liver was incubated with epinephrine and S-adenosyl-methionine (5), and that metanephrine was excreted in the urine of rats, both under normal conditions and after the intraperitoneal administration of $l$-epinephrine bitartrate (5).

The magnitude of the O-methylation pathway in rats was estimated by Axelrod, Inscoe, Senoh and Witkop. They concluded that about 70 per cent of epinephrine was O-methylated (6). In 1958 a preliminary report was published by LaBrosse, Axelrod and Kety, which indicated that O-methylation was also the principal route of metabolism of epinephrine in man (7).

Earlier studies on epinephrine metabolism in man (7-10) were necessarily limited by insufficient knowledge of the nature of the metabolites, lack of adequate methods for their quantification or incomplete accountability of the excretion of the infused radioactivity, and accurate evaluation of the alternate pathways was not possible.

The recent identification of an additional metabolite of epinephrine, 3-methoxy-4-hydroxyphenylglycol, by Axelrod, Kopin and Mann (11), the use or development of improved methods for the separation and estimation of this and other metabolites, and the advantages associated with the use of tritium-labeled epinephrine of high specific activity have warranted a further examination of the metabolites of epinephrine in man.

\section{METHODS}

Materials. d,l-Epinephrine-7- $\mathrm{H}^{3}$-d-bitartrate (specific activity $5.0 \mathrm{mc}$ per $\mathrm{mg}$ ) was used. ${ }^{1}$ When developed in both the phenol:0.01 $\mathrm{N} \mathrm{HCl}-\mathrm{SO}_{2} \quad(80: 20)$ and the $n$-butanol:acetic acid: water $(4: 1: 1)$ systems, chromatograms of this tritium-labeled epinephrine showed one peak of radioactivity corresponding to authentic epinephrine-d-bitartrate. The tritium label $\left(7-\mathrm{H}^{3}\right)$ of epinephrine did not exchange with the hydrogen in the water of aqueous solutions of this compound when stored in 2 per cent sodium metabisulfite solution for several months at $4^{\circ}$ to $8^{\circ} \mathrm{C}$.

Administration of epinephrine. $d, l$-Epinephrine-7- $\mathrm{H}^{3}-\mathrm{d}-$ bitartrate, alone or with added unlabeled $l$-epinephrine-dbitartrate, was infused intravenously at rates of approximately $0.3 \mu \mathrm{g}$ of $l$-epinephrine base per $\mathrm{kg}$ per minute or $0.18 \mu \mathrm{g}$ per $\mathrm{kg}$ per minute for 30 -minute periods to 12 normal young men, 18 to 22 years of age, weighing from 59.4 to $79.1 \mathrm{~kg}$. The total dose ranged from 311 to 1,101 $\mu \mathrm{g}$ of $l$-epinephrine (free base), and specific activity ranged from 342 to $971 \mu \mathrm{c}$ per $\mathrm{mg}$. The details of its administration and the results of physiological (12) and psychiatric studies (13) on these subjects are reported elsewhere.

Collection of urine and determination of total radioactivity. Urine was collected without preservative for

\footnotetext{
1 Prepared by the New England Nuclear Corporation by the reduction of adrenalone with lithium aluminum tritide; labile tritium was removed, and the $d, l$ epinephrine-7- $\mathrm{H}^{3}$-d-bitartrate was obtained as a grayishwhite powder.
} 
54 hours following the infusion and was promptly refrigerated until analyzed or stored in the deepfreeze if the analysis was delayed. The total radioactivity in each of the urine specimens was determined by a modification of the method of Okita, Spratt and Leroy (14) by adding $0.1 \mathrm{ml}$ of urine to a mixture of $4 \mathrm{ml}$ of ethanol and $10 \mathrm{ml}$ of 0.4 per cent 2,4-diphenyloxazole and 0.01 per cent $\beta$-bis (2-phenyloxazole) benzene in toluene ("ethanolfluor"). Radioactivity was assayed in a liquid scintillation spectrometer. Duplicate portions of urine were used throughout in these studies. With all samples, correction for quenching was made by counting before and after the addition of tritium internal standard, and correction for partition was made by using authentic compounds in the respective extraction procedure. Since difficulties are usually encountered in obtaining complete urine collections, the values for total urinary radioactivity which were obtained are probably underestimates.

Estimation of metanephrine. Free metanephrine was determined in duplicate $2 \mathrm{ml}$ portions of the urine specimens, by adjustment to $\mathrm{pH} 10$ with $6 \mathrm{~N} \mathrm{NaOH}$ and 0.2 $\mathrm{ml}$ of $\mathrm{pH} 10$ borate buffer $(0.8 \mathrm{M})$, followed by extraction with $10 \mathrm{ml}$ of isoamyl alcohol. After centrifugation, a $4 \mathrm{ml}$ portion of the isoamyl alcohol phase was transferred to vials containing the ethanol-fluor solution and the radioactivity was assayed in the scintillation spectrometer.

Metanephrine glucuronide was determined by adding $0.2 \mathrm{ml}$ of $\mathrm{pH} 6.5$ acetate buffer containing $1,400 \mathrm{U}$ of bacterial $\beta$-glucuronidase (Sigma) and 6 drops $(0.3 \mathrm{ml}$ ) of chloroform to $2-\mathrm{ml}$ portions of the urine. The urine was incubated for 3 hours at $37^{\circ} \mathrm{C}$. After the incubation, $1.8 \mathrm{ml}$ of borate buffer $(\mathrm{pH} 10,0.8 \mathrm{M})$ was added and the solutions were extracted with isoamyl alcohol. Four-ml portions of the isoamyl alcohol extract were counted for radioactivity as above. This isoamyl extract obtained following glucuronidase hydrolysis contains the initial free metanephrine and metanephrine released by the enzyme. Therefore, radioactivity in the metanephrine glucuronide was calculated by subtracting that in the free metanephrine from that obtained after $\beta$-glucuronidase hydrolysis.

Metanephrine sulfate was determined by acid hydrolysis followed by extraction at $\mathrm{pH} 10$ as follows: $\mathrm{Six} \mathrm{N}$ $\mathrm{HCl}, 0.4 \mathrm{ml}$, was added to $2-\mathrm{ml}$ portions of the urine and the solutions were kept at $37^{\circ} \mathrm{C}$ for 48 hours in a water bath. The hydrolysates were adjusted to $\mathrm{pH} 10$ with 0.4 $\mathrm{ml}$ of $6 \mathrm{~N} \mathrm{NaOH}$ and $0.4 \mathrm{ml}$ of $\mathrm{pH} 10$ borate buffer $(0.8$ $\mathrm{M})$. After extraction with $10 \mathrm{ml}$ of isoamyl alcohol and centrifugation, two 4-ml portions of the organic phase were taken for determination of the radioactivity. Under the conditions of acid hydrolysis, a negligible amount of the metanephrine is freed from the glucuronide; therefore, the radioactivity which is extracted at $\mathrm{pH} 10$ after the acid hydrolysis arises from free metanephrine and hydrolyzed metanephrine sulfate. Subtraction of the "free" metanephrine gives the value for the metanephrine sulfate. When corrections were made for the aliquots which were used, authentic metanephrine carried through these procedures gave recoveries of 80,76 , and 70 per cent for the procedures for estimation of free metanephrine, metanephrine glucuronide, and metanephrine sulfate, respectively. These recoveries were used in calculating the amount of radioactivity represented by each of the metabolites.

Estimation of 3-mcthoxy-4-hydroxymandelic acid $(V M A)$. VMA was estimated in $2-\mathrm{ml}$ portions of urine by adjusting the urine to $\mathrm{pH} 1$ with $\mathrm{HCl}$ and extracting with $20 \mathrm{ml}$ of isoamyl alcohol. Fifteen $\mathrm{ml}$ of the isoamyl alcohol phase was shaken with $3 \mathrm{ml}$ of 5 per cent sodium bicarbonate. Two $\mathrm{ml}$ of the sodium bicarbonate extract was adjusted to $\mathrm{pH} 1$ with $\mathrm{HCl}$ and extracted with 10 $\mathrm{ml}$ of isoamyl alcohol. Radioactivity in two 4-ml portions of the isoamyl alcohol was determined as above. Authentic VMA gave a recovery of 80 per cent when carried through this procedure. Corrections for quenching, aliquoting and partition were made as above for the metanephrine metabolites.

As a check on the extraction procedure, VMA was also determined by chromatography on silica gel. Silica gel columns were prepared by adding $2.5 \mathrm{ml}$ of $0.5 \mathrm{~N}$ $\mathrm{H}_{2} \mathrm{SO}_{4}$ to $4 \mathrm{~g}$ of dry silica gel. This acidified silica gel, a free-flowing powder, was suspended in chloroform and poured into a column $1 \mathrm{~cm}$ in diameter to a height of 5 $\mathrm{cm}$. A $1 \mathrm{ml}$ portion of urine was acidified with $0.1 \mathrm{ml}$ of $10 \mathrm{~N} \mathrm{H}_{2} \mathrm{SO}_{4}$, mixed with $2 \mathrm{~g}$ of dry silica gel and added to the column. The column was topped with a snug-fitting filter paper disc and washed with $20 \mathrm{ml}$ of chloroform. The VMA was eluted with $80 \mathrm{ml}$ of 5 per cent $n$-butanol in chloroform. Recoveries of authentic $\mathrm{H}^{3}$-VMA added to urine were 90 to 95 per cent. Determination of VMA by the extraction procedure and by chromatography on silica gel showed good agreement (respectively, 41.2 and 40.6 per cent average of the radioactivity in the urine).

The specificity of these procedures is shown by the presence of one peak of radioactivity which corresponds to the position of authentic compounds on paper chromatograms of these fractions (see Figures $1 \mathrm{~A}$ and 1B).

Estimation of free epinephrine in urine. Free epinephrine in the urine was determined by chromatography of $10-\mathrm{ml}$ portions of the urine on alumina columns (15). Dry nonalkaline alumina (Woelm) was poured into columns $1 \mathrm{~cm}$ in diameter to a height of $4 \mathrm{~cm}$, and washed with $10 \mathrm{ml}$ of $0.5 \mathrm{M}$ borate buffer, $\mathrm{pH} 8.3$, followed by $20 \mathrm{ml}$ of glass-distilled water. One $\mathrm{ml}$ of 1 per cent sodium ethylenediamine tetraacetic acid (EDTA), $1 \mathrm{mg}$ of nonradioactive $l$-epinephrine-d-bitartrate, and $1 \mathrm{ml}$ of $\mathrm{pH}$ 8.3 borate buffer $(0.5 \mathrm{M})$ were added to $10-\mathrm{ml}$ portionc of urine. The urine was adjusted with $3 \mathrm{~N} \mathrm{NaOH}$ to $\mathrm{pH} 8.3$ (measured with a glass electrode), and poured through the column. The column was washed with $50 \mathrm{ml}$ of glass-distilled water containing 0.1 per cent EDTA, and the epinephrine was eluted with $20 \mathrm{ml}$ of $1 \mathrm{~N}$ acetic acid. Aliquots of the acetic acid eluate were concentrated by lyophilization; $0.2 \mathrm{ml}$ of distilled water and 10 $\mathrm{ml}$ of the ethanol-fluor were added, and the radioactivity was assayed as above. The recoveries of added epinephrine were $100 \pm 5$ per cent, measured by direct fluorimetry of the acetic acid eluates, and specificity of the eluted 

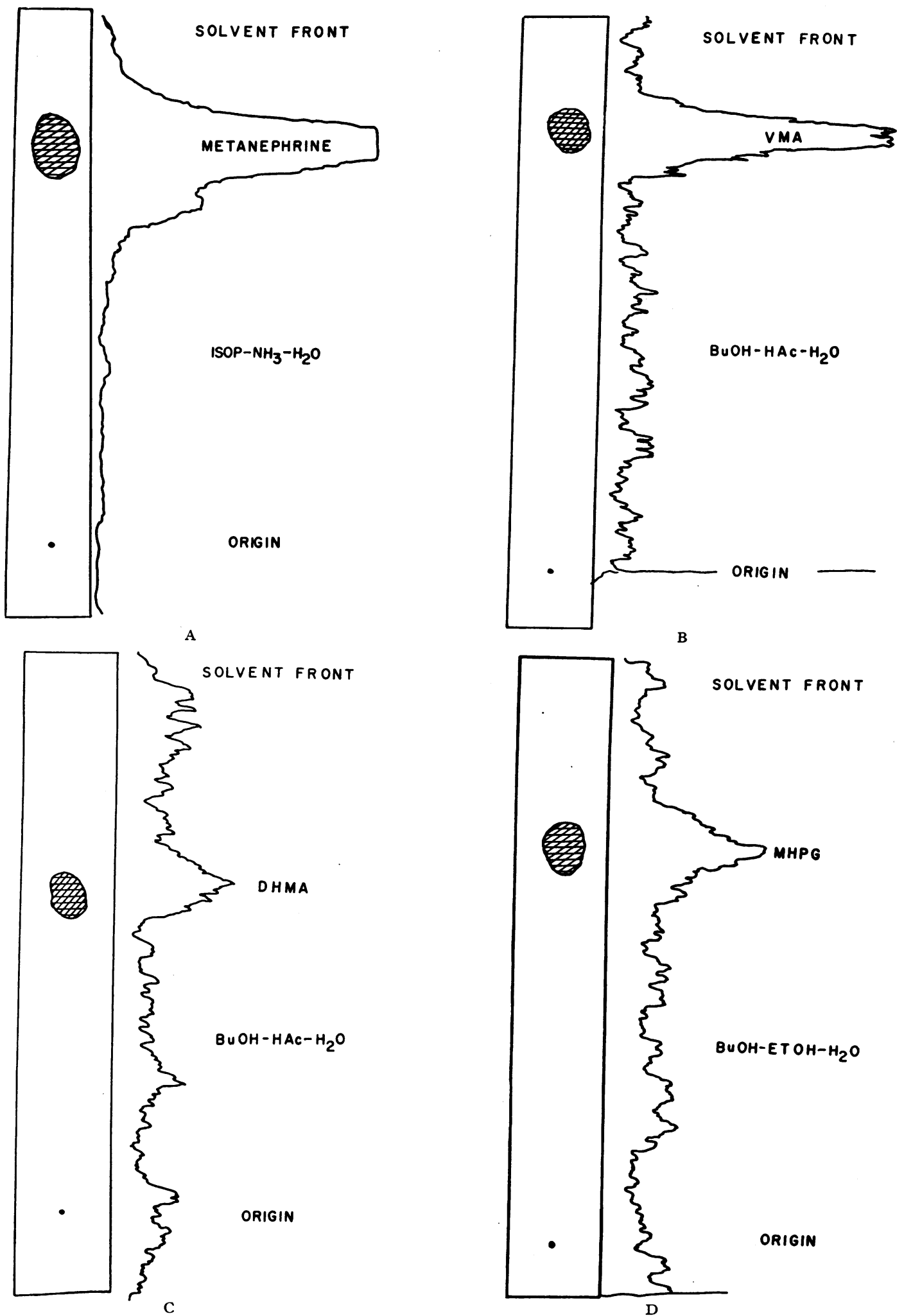

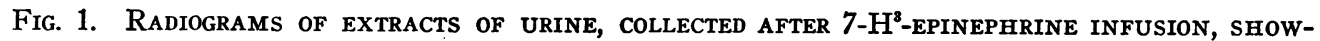
ING SPECIFICITY OF THE EXTRACTED MATERIAL. A) Metanephrine = 3-O-methyl-epinephrine; B) VMA =3-methoxy-4-hydroxymandelic acid; C) DHMA =3,4-dihydroxymandelic acid; D) $M H P G=3-$ methoxy-4-hydroxyphenylglycol. 
radioactivity was demonstrated by the presence of a single peak of radioactivity corresponding to the locations of authentic epinephrine on paper chromatograms in $n$-butanol: acetic acid: water $(4: 1: 1)$ and in phenol: $0.01 \mathrm{~N}$ $\mathrm{HCl}-\mathrm{SO}_{2}(80: 20)$ systems.

Estimation of free 3,4-dihydroxymandelic acid $(D H M A)$. One-tenth vol of 1 per cent EDTA and 0.02 vol of freshly prepared 2 per cent ascorbic acid solution were added to an aliquot containing about $1 \mu \mathrm{c}$ total radioactivity in the urine. The $\mathrm{pH}$ was adjusted to 8.4 by the addition of $1 \mathrm{~N} \mathrm{NaOH}$ (using a glass electrode), and the final volume was adjusted to $120 \mathrm{ml}$ by the addition of glass-distilled water. The solution was centrifuged and $100 \mathrm{ml}$ of the supernatant solution was poured through a $3 \mathrm{~cm}$ high, $0.4 \mathrm{~cm}$ diameter column of alumina (Woelm, nonalkaline). Ten $\mathrm{ml}$ of $0.2 \mathrm{M}$ sodium acetate solution ( $\mathrm{pH} 8.4)$ and $10 \mathrm{ml}$ of glass-distilled water were also passed through the column in that order. The free catechols (epinephrine and DHMA) were eluted from the column with $30 \mathrm{ml}$ of $0.2 \mathrm{~N} \mathrm{H}_{2} \mathrm{SO}_{4}$. The sulfuric acid eluate was extracted with 5 vol of ethyl acetate. No epinephrine is extracted under these conditions, but 45 per cent of the DHMA passes into the ethyl acetate phase. The ethyl acetate extract was evaporated to dryness in vacuo, and the residue dissolved in $5 \mathrm{ml}$ of ethanol. Four $\mathrm{ml}$ of the resulting ethanol solution was added to $10 \mathrm{ml}$ of the toluene-fluor and the radioactivity was determined as mentioned above.

Estimation of conjugated DHMA. The conjugated DHMA was determined in the combined effluent and washings from the alumina column used for determination of free DHMA. The combined solution was adjusted to $\mathrm{pH} 1$ with $\mathrm{HCl}$ and heated on a steam bath for 1 hour. After cooling, 0.1 vol of 1 per cent EDTA, 0.02 vol of freshly prepared 2 per cent ascorbic acid solution and $10 \mu \mathrm{g}$ of authentic DHMA were added, and the resulting solution was adjusted to $\mathrm{pH} 8.4$, chromatographed on alumina, extracted, concentrated and counted as described above for free DHMA.

The specificity of the procedure for DHMA was indicated by the finding of a major peak ( 85 per cent of radioactivity) at $\operatorname{Rf} 0.58$ which corresponded to authentic DHMA on paper chromatograms developed in $n$-butanol: acetic acid: water $(4: 1: 1)$ (see Figure 1C). A second smaller peak at $\operatorname{Rf} 0.81$, increased after storage of the extract in the refrigerator for 1 day, indicating that it was a breakdown product of the DHMA.

Estimation of 3-methoxy-4-hydroxyphenylglycol $(M H P G)$. One-tenth vol of the combined effluent and washing from the alumina column used in the determination of the free DHMA (see above) was adjusted to pH 11.5 with $3 \mathrm{~N} \mathrm{NaOH}$; solid $\mathrm{BaCl}_{2}$ was added and the precipitated phosphate and sulfate were centrifuged until well packed at the bottom of the tube. An aliquot of the supernatant solution was adjusted to $\mathrm{pH} 6.5$ with $3 \mathrm{~N}$ acetic acid, sulfatase (Gilusulase, Endo Products, $\mathrm{N}$. Y.) was added to a final concentration of $1,000 \mathrm{U}$ per $\mathrm{ml}$, and the mixture was incubated at $37^{\circ} \mathrm{C}$ for 24 hours. The solutions were centrifuged and an aliquot of the supernatant solution was poured onto a $7.5 \mathrm{~cm}$ column of Dowex-50 ion exchange resin. ${ }^{2}$ The column was washed with an equal volume of water. The effluent and washings were combined, saturated with sodium chloride, and extracted with 5 vol of ethyl acetate. About 85 per cent of the MHPG was extracted under these conditions. An aliquot of the ethyl acetate extract containing at least $60 \mathrm{~m} \mu \mathrm{c}$ of radioactivity was evaporated under a current of warm air in a scintillation counting vial, ${ }^{3}$ the residue was dissolved in $14 \mathrm{ml}$ of the ethanolfluor mixture and counted. The specificity of this procedure was indicated by the presence of a single peak of radioactivity corresponding to authentic MHPG in the $n$-butanol: acetic acid: water $(4: 1: 1)$, isopropanol: $7 \mathrm{~N}$ ammonia $(4: 1)$, and $n$-butanol: ethanol: water $(4: 1: 1)$ systems (see Figure 1D).

\section{RESULTS}

The infused tritium was almost quantitatively excreted in the urine within 54 hours; the median value of excretion was 94.5 per cent. Water was distilled from several specimens of the urine collected after the $\mathrm{H}^{3}$-epinephrine infusions and was assayed for tritium content. No measurable amount of radioactivity was found in the water of these urine specimens. It has also been established that the methods described above for the quantification of the individual metabolites do not result in measurable loss of the tritium label.

An average of 97 per cent $(\mathrm{SE} \pm 4.0)$ of the tritium in the urine has been accounted for by the metabolites which were measured in this study (see Table I). The catechols, constituting 8.4 per cent of the tritium in the urine, are made up of epinephrine (6.8 per cent) and total DHMA (1.6 per cent). The 3-methoxy compounds totaled 89.2 per cent: these were free and conjugated metanephrine, 40.8 per cent; VMA, 41.2 per cent; and MHPG, 7.1 per cent.

\section{DISCUSSION}

In 11 of the 12 subjects listed in Table $\mathrm{I}, d, l-\mathrm{H}^{3}-$ epinephrine was used; therefore, the urinary tritium came equally from the $d$ - and $l$-isomers. At considerable cost in material a small quantity of $l$ - $\mathrm{H}^{3}$-epinephrine-d-bitartrate was obtained by

2 The Dowex -50 resin was prepared by soaking overnight in $3 \mathrm{~N} \mathrm{NH}{ }_{4} \mathrm{OH}$ and washing until the effluent was neutral when tested with $\mathrm{pH}$ paper.

3 Low potassium, No-sol-vit glass liquid scintillation spectrometer vials, $20 \mathrm{ml}$ capacity, with polyethylene snap-cap, were obtained from the Wheaton Glass Company, Millville, N. J. 
TABLE I

Urinary metabolites following infusion of $H^{3}$-epinephrine in normal young men *

\begin{tabular}{|c|c|c|c|c|c|c|c|c|c|c|c|c|c|c|c|c|c|}
\hline \multirow{3}{*}{\multicolumn{2}{|c|}{ Subjects }} & & & & & \multirow{4}{*}{$\begin{array}{l}\text { Per cent } \\
\text { of inf. } \\
\text { tritium } \\
\text { excreted }\end{array}$} & \multicolumn{11}{|c|}{ Metabolites expressed as per cent of tritium in the urine } \\
\hline & & \multicolumn{4}{|c|}{ Total dose } & & \multicolumn{4}{|c|}{ ME } & \multirow[b]{2}{*}{ VMA } & \multirow[b]{2}{*}{ Epi } & \multirow[b]{2}{*}{ MHPG } & \multicolumn{3}{|c|}{ DHMA } & \multirow{2}{*}{$\begin{array}{c}\text { Total } \\
\text { of } \\
\text { metab- } \\
\text { olites }\end{array}$} \\
\hline & & \multicolumn{2}{|c|}{$l$-Epi. } & \multicolumn{2}{|c|}{$d$-Epi. } & & Free & Gluc. & Sulfate & $\begin{array}{l}\text { Total } \\
\text { ME }\end{array}$ & & & & Free & Conj. & Total & \\
\hline no. & & $\mu g$ & $\mu c$ & $\mu g$ & $\mu c$ & & & & & & & & & & & & \\
\hline $\begin{array}{r}2 \\
4 \\
6 \\
8 \\
10 \\
12 \\
14 \\
16 \\
18 \\
20 \\
22 \\
24\end{array}$ & $\begin{array}{l}\text { R. A. } \\
\text { D. G. } \\
\text { R. C. } \\
\text { P. G. } \\
\text { R. B. } \\
\text { M. Y. } \\
\text { D. H. } \\
\text { M. D. N. } \\
\text { D. S. } \\
\text { L. S. } \\
\text { D. S. P. } \\
\text { D. W. }\end{array}$ & $\begin{array}{r}1,101 \\
1,012 \\
930 \\
1,064 \\
453 \\
393 \\
445 \\
403 \\
311 \\
399 \\
410 \\
321\end{array}$ & $\begin{array}{l}178 \\
173 \\
200 \\
182 \\
211 \\
216 \\
207 \\
188 \\
158 \\
228 \\
199 \\
156\end{array}$ & $\begin{array}{r}367 \\
337 \\
310 \\
355 \\
453 \\
393 \\
445 \\
403 \\
23 \\
0 \\
410 \\
321\end{array}$ & $\begin{array}{l}178 \\
173 \\
200 \\
182 \\
211 \\
216 \\
207 \\
188 \\
158 \\
0 \\
199 \\
156\end{array}$ & $\begin{array}{r}78 \\
84 \\
93 \\
100 \\
99 \\
88 \\
96 \\
89 \\
100 \\
96 \\
103 \\
86\end{array}$ & $\begin{array}{l}6 \\
6 \\
4 \\
6 \\
6 \\
4 \\
7 \\
4 \\
4 \\
5 \\
6 \\
5\end{array}$ & $\begin{array}{l}4 \\
4 \\
6 \\
6 \\
5 \\
8 \\
5 \\
7 \\
8 \\
6 \\
5 \\
8\end{array}$ & $\begin{array}{l}22 \\
24 \\
19 \\
34 \\
42 \\
46 \\
27 \\
20 \\
21 \\
30 \\
31 \\
38\end{array}$ & $\begin{array}{l}32 \\
34 \\
29 \\
46 \\
53 \\
58 \\
39 \\
31 \\
33 \\
41 \\
42 \\
51\end{array}$ & $\begin{array}{l}38 \\
41 \\
28 \\
36 \\
51 \\
36 \\
59 \\
39 \\
48 \\
40 \\
34 \\
45\end{array}$ & $\begin{array}{l}9 \\
7 \\
7 \\
7 \\
4 \\
6 \\
5 \\
7 \\
7 \\
9 \\
5 \\
8\end{array}$ & $\begin{array}{l}8.4 \\
5.4 \\
4.5 \\
6.1 \\
7.2 \\
7.9 \\
5.9 \\
7.5 \\
7.6 \\
7.9 \\
9.1 \\
8.2\end{array}$ & $\begin{array}{l}0.61 \\
0.76 \\
0.00 \\
0.77 \\
0.52 \\
0.31 \\
0.81 \\
0.52 \\
1.14 \\
0.94 \\
0.66 \\
0.94\end{array}$ & $\begin{array}{l}0.96 \\
1.10 \\
0.04 \\
1.00 \\
0.49 \\
1.26 \\
1.31 \\
1.20 \\
0.65 \\
0.80 \\
1.22 \\
1.16\end{array}$ & $\begin{array}{l}1.57 \\
1.86 \\
0.04 \\
1.77 \\
1.01 \\
1.57 \\
2.12 \\
1.72 \\
1.79 \\
1.74 \\
1.88 \\
2.10\end{array}$ & $\begin{array}{r}89 \\
89 \\
68 \\
97 \\
116 \\
109 \\
111 \\
86 \\
97 \\
100 \\
92 \\
114\end{array}$ \\
\hline \multirow{2}{*}{24} & Mean & & & & & 92.6 & 5.2 & 6.0 & 29.5 & 40.8 & 41.2 & 6.8 & 7.1 & 0.66 & 0.93 & 1.60 & 97 \\
\hline & SD & & & & & 7.7 & 1.1 & 1.5 & 9.0 & 9.5 & 8.4 & 1.5 & 1.4 & 0.31 & 0.38 & 0.57 & 14 \\
\hline
\end{tabular}

* $l$-Epi and $d$-Epi $=l$ - and $d$-epinephrine (free base); Inf. =infused; Gluc. =glucuronide; ME $=$ metanephrine; VMA $=3$-methoxy-4-hydroxymandelic acid; $M H P G=3$-methoxy-4-hydroxyphenylglycol; DHMA =3,4-dihydroxymandelic acid; Conj. =conjugated.

resolution of the racemic material. ${ }^{4}$ The $l-\mathrm{H}^{3}-$ epinephrine was used for the infusion of Subject 20 shown in Table I, in a schizophrenic patient infused in part of the study $(12,14)$, and in two subjects used by Kopin (16). In all four of these subjects in which the $l-\mathrm{H}^{3}$-epinephrine was used, the distribution of the tritium among the epinephrine metabolites did not differ significantly from that found after the racemic $\mathrm{H}^{3}$-epinephrine. This finding in man is in agreement with the finding of Schayer, Smiley and Kaplan in rats that the urinary chromatographic pattern of excretion was not significantly different after the $d$-and $l-\beta$ - $C^{14}$ epinephrine (17).

Since Axelrod's demonstration of the O-methylation pathway of epinephrine metabolism in rats

4 The resolution was accomplished by adding $5.1 \mathrm{mg}$ of nonradioactive $l$-epinephrine-d-bitartrate to $4.6 \mathrm{mg}$ of $d, l$ $\mathrm{H}^{3}$-epinephrine-d-bitartrate and dissoliving in $15 \mu \mathrm{l}$ of water plus $90 \mu \mathrm{l}$ of absolute methanol. After standing in the freezer at $-10^{\circ} \mathrm{C}$ for three days, the vial was brought to room temperature and the slightly brownish solution was treated with charcoal. The tube was centrifuged, the supernatant solution was decanted into a $5 \times$ $50 \mathrm{~mm}$ test tube, and the solvent was removed by distillation in vacuo. As the solution became concentrated, crystals formed in the slightly brownish, syrupy liquid on the sides of the tube. The crystals were washed with methanol and dried in a vacuum desiccator. The dry crystals weighed $0.88 \mathrm{mg}$ (12 per cent yield). The small quantity of this material made optical rotatory measurements impractical; however, bioassay by rat blood pressure measurements indicated that it contained $>90$ per cent $l$-epinephrine.
(5), the question of the presence and quantitative importance of this pathway in man has been of increasing interest. Resnick and Elmadjian (9) have reported that 34 per cent of the radioactivity of infused $\mathrm{N}$-methyl- $\mathrm{C}^{14}$-epinephrine was excreted in the urine of human subjects. This result indicated that approximately one-third of infused epinephrine did not lose its side chain. Since only 1 to 5 per cent of the infused epinephrine was excreted unchanged, the remaining 29 to 33 per cent must have been a metabolite with the side chain intact. Later studies by Resnick, Wolfe, Freeman and Elmadjian (18), Kirshner, Goodall and Rosen (10), and LaBrosse and co-workers (7), have shown that this metabolite is metanephrine, the O-methylation product of epinephrine. Kirshner and associates (19) have stated "that monoamine oxidase plays an important role in the inactivation of epinephrine at least in the short period of time after an infusion when it has physiological activity." This conclusion is difficult to accept because of the general lack of potentiation of the physiological effects of epinephrine by monoamine oxidase inhibitors. Furthermore, Kirshner and co-workers (19) base this conclusion on the finding that the radioactivity in the epinephrine fraction of the urine is doubled as a result of iproniazid treatment. However, calculation from their data reveals that this increase represents a change from 2.0 to 3.6 per cent of the infused epinephrine, and this change was found only during the initial 
collection period. This small and evanescent difference in the excreted epinephrine, in view of the numerous variables involved, does not seem to merit the broad conclusion drawn. In contrast, the following evidence in the present report confirms previous reports from this laboratory (5-7) indicating that O-methylation is the principal pathway in the metabolism of circulating epinephrine. Following an infusion of $\beta-\mathrm{H}^{3}$-epinephrine to a total of 12 human subjects, 40.8 per cent of total 54-hour urinary radioactivity has been found to be free and conjugated metanephrine. An indication of the proportion of metanephrine which is further metabolized to VMA and MHPG can be obtained by studying the excretion of these metabolites following infusion of labeled metanephrine. When $7-\mathrm{H}^{3}$-metanephrine was infused intravenously, 50 per cent of the radioactivity in the urine was found to be free and conjugated metanephrine and 25 per cent was found to be VMA. If it is assumed that the ratio of VMA to metanephrine, excreted after metanephrine is infused, is indicative of the manner in which endogenously formed metanephrine is metabolized, then it can be calculated that half of the VMA (or 20.6 per cent of the total urinary radioactivity) would have been formed via metanephrine after the $7-\mathrm{H}^{3}$-epinephrine infusion. In the present study an additional 3-methoxylated metabolite, MHPG, has been quantified. Kopin (16) has shown that about half of the latter metabolite, MHPG, as well as VMA, is formed by 3-O-methylation prior to deamination. Therefore, of the 7.1 per cent of the total urinary tritium which is $\mathrm{H}^{3}$-MHPG in the study reported here, 3.6 per cent probably had undergone $\mathrm{O}$-methylation to metanephrine prior to deamination to MHPG. Therefore, of the total urinary radioactivity, 40.8 per cent (free and conjugated metanephrine), 20.6 per cent (VMA formed from metanephrine) and 3.6 per cent MHPG formed from metanephrine) or a total of 65 per cent of the urinary radioactivity was in metabolites formed from the tritium-labeled epinephrine by 3-O-methylation as the first step in its metabolism. This finding agrees well with the 67 per cent O-methylation obtained in a definitive study by Kopin (16) in which $l-7-\mathrm{H}^{3}$-epinephrine and l-3-methoxy-C ${ }^{14}$-metanephrine were administered simultaneously to human subjects.
These findings present support for the hypothesis that 3-O-methylation is the principal pathway of metabolism for circulating epinephrine in man, at several pharmacological dosage levels as well as in the tracer dose (12.6 $\mu \mathrm{g}$ of $l$-epinephrine base), which was used by Kopin in the double-labeled experiments (16). It is of interest, that almost identical results were obtained with $l$ - and $d l-7-\mathrm{H}^{3}-$ epinephrine in this and the experiments which utilized the double label (16).

Considering the question of whether monoamine oxidase or catechol-O-methyl transferase is the more important enzyme in the metabolic inactivation of epinephrine, Griesemer and colleagues (20) have reported that monoamine oxidase inhibitors do not potentiate the action of epinephrine. Also, Friend, Zileli, Hamlin and Reutter (21) have shown that administration of iproniazid (a monoamine oxidase inhibitor) does not alter the blood pressure, pulse rate, or other physiological effects of a norepinephrine infusion in man. It has been shown after labeled epinephrine that iproniazid decreases the urinary excretion of VMA, but increases the excretion of metanephrine (18). Hence, iproniazid does not inhibit catechol-Omethyl transferase. On the other hand, Bacq demonstrated many years ago that pyrogallol and several catechols potentiate the action of epinephrine (22). Recently, Bacq, Gosselin, Dresse and Renson have shown that catechol inhibits the action of O-methyl transferase on epinephrine in vitro, and they suggest that this inhibition is the mechanism for the sensitization of smooth muscle to epinephrine by catechols (23). Axelrod and Laroche have shown that pyrogallol is an effective inhibitor of catechol-O-methyl transferase, both in vitro and in vivo (24). From these reports it is known that pyrogallol and several catechols potentiate the action of epinephrine and simultaneously inhibit the action of the enzyme involved in the principal pathway of metabolism of this catechol amine. Furthermore, the O-methylated products are virtually inactive compared to the parent catechol amine $(7,25)$. These findings are compatible with the thesis that O-methylation is involved in the physiological inactivation of epinephrine and norepinephrine.

Within the past three years the recovery of infused, and presumably endogenous, epinephrine 
in terms of known metabolites has increased from a few per cent to practically complete accountability, as shown in the present study. An opportunity is now provided for a more precise evaluation of the endogenous production of the catechol amine hormones or their abnormal degradation in various clinical states.

\section{SUMMARY}

The metabolism of $7-\mathrm{H}^{3}$-epinephrine-d-bitartrate was studied in normal young men. An average of 92.6 per cent $(\mathrm{SD} \pm 7.7)$ of the infused radioactivity was excreted in the urine within 54 hours. The tritium-labeled metabolites were isolated, and gave the following percentages (mean \pm SD) of total radioactivity in the urine: unchanged epinephrine, $6.8 \pm 1.5$; free metanephrine, $5.2 \pm$ 1.1 ; metanephrine glucuronide, $6.0 \pm 1.5$; metanephrine sulfate, $29.5 \pm 9.0$; 3-methoxy-4-hydroxyphenylglycol, $7.1 \pm 1.4$; free 3,4-dihydroxymandelic acid (DHMA), $0.7 \pm 0.3$; and conjugated DHMA, $0.9 \pm 0.4$. The isolated metabolites averaged 97 per cent $(\mathrm{SE} \pm 4.0)$ of the total urinary radioactivity.

The relevance of these findings to the routes of epinephrine metabolism is discussed and, in the light of present knowledge, they support the thesis that $\mathrm{O}$-methylation followed by deamination is the major route of metabolic inactivation of circulating epinephrine.

\section{ACKNOWLEDGMENT}

The technical assistance of Frank Sordyl, Mary R. Ferguson, Samuel Newberry, George Canty and Edna Gordon is gratefully acknowledged.

\section{REFERENCES}

1. Schayer, R. W. Studies of metabolism of $\beta$-C $\mathrm{C}^{14}-\mathrm{dl}-$ adrenalin. J. biol. Chem. 1951, 189, 301.

2. Schayer, R. W., and Smiley, R. L. The metabolism of epinephrine containing isotopic carbon. J. biol. Chem. 1953, 202, 425.

3. Schayer, R. W., Smiley, R. L., Davis, K. J., and Kobayashi, Y. Role of monoamine oxidase in noradrenaline metabolism. Amer. J. Physiol. 1955, 182, 285.

4. Armstrong, M. D., McMillan, A., and Shaw, K. N. F. 3-Methoxy-4-hydroxy-d-mandelic acid, a urinary metabolite of norepinephrine. Biochim. biophys. Acta 1957, 25, 422.
5. Axelrod, J. O-Methylation of epinephrine and other catechols in aitro and in vivo. Science 1958, 126, 400.

6. Axelrod, J., Inscue, J. K., Senoh, S., and Witkop, B. O-Methylation, the principal pathway for the metabolism of epinephrine and norepinephrine in the rat. Biochim. biophys. Acta 1958, 27, 210.

7. LaBrosse, E. H., Axelrod, J., and Kety, S. S. O-Methylation, the principal route of metabolism of epinephrine in man. Science 1958, 128, 593.

8. Resnick, O., and Elmadjian, F. Excretion and metabolism of dl-epinephrine-7- $\mathrm{C}^{\mathbf{1 4}}$-d-bitartrate infused into schizophrenic patients (abstract). Amer. J. Physiol. 1956, 187, 626.

9. Resnick, O., and Elmadjian, F. The metabolism of epinephrine-containing isotopic carbon in man. J. clin. Endocr. 1958, 18, 28.

10. Kirshner, N., Goodall, McC., and Rosen, L. Metabolism of dl-adrenaline-2- $\mathrm{C}^{14}$ in the human. Proc. Soc. exp. Biol. (N. Y.) 1958, 98, 627.

11. Axelrod, J., Kopin, I. J., and Mann, J. D. 3-Methoxy4-hydroxyphenylglycol sulfate, a new metabolite of epinephrine and norepinephrine. Biochim. biophys. Acta 1959, 36, 576.

12. Cardon, P. V., Jr., Sokoloff, L., Vates, T. S., Evarts, E. V., and Kety, S. S. The physiological and psychological effects of intravenously administered epinephrine, and its metabolism, in normal and schizophrenic men. I. Effects on heart rate, blood pressure, blood glucose concentration and the electroencephalogram. J. psychiat. Res. In press.

13. Pollin, W., and Goldin, S. The physiological and psychological effects of intravenously administered epinephrine, and its metabolism, in normal and schizophrenic men. II. Mental and behavioral effects. J. psychiat. Res. In press.

14. Okita, G. T., Spratt, J., and Leroy, G. V. Liquidscintillation counting for assay of tritium in urine. Nucleonics 1956, 14, no. 3, 76.

15. Weil-Malherbe, H., and Bone, A. D. The chemical estimation of adrenaline-like substances in blood. Biochem. J. 1952, 51, 311.

16. Kopin, I. J. Technique for the study of alternate metabolic pathways; epinephrine metabolism in man. Science 1960, 131, 1372.

17. Schayer, R. W., Smiley, R. L., and Kaplan, E. H. The metabolism of epinephrine containing isotopic carbon. J. biol. Chem. 1952, 198, 545.

18. Resnick, O., Wolfe, J. M., Freeman, H., and Elmadjian, F. Iproniazid treatment and metabolism of labeled epinephrine in schizophrenia. Science 1958, 127, 1116.

19. Kirshner, N., Goodall, McC., and Rosen, L. The effect of -iproniazid on the metabolism of dl-epinephrine-2- $\mathrm{C}^{14}$ in the human. J. Pharmacol. exp. Ther. 1959, 127, 1.

20. Griesemer, E. C., Barsky, J., Dragstedt, C. A., Wells, J. A., and Zeller, E. A. Potentiating effect of iproniazid on the pharmacological action of sym- 
pathomimetic amines. Proc. Soc. exp. Biol (N. Y.) 1953, 84, 699.

21. Friend, D. G., Zileli, M. S., Hamlin, J. 'T., and Reutter, F. W. The effect of iproniazid on the inactivation of norepinephrine in the human. J. clin. exp. Psychopath. 1958, 19(2), suppl. 1, 61.

22. Bacq, Z. M. Recherches sur la physiologie et la pharmacologie du système nerveaux autonome. $\mathrm{XX}$. Sensibilisation à l'adrénaline et à l'excitation des nerfs adrénergiques par les antioxygènes. Arch. int. Physiol. 1936, 42, 340 .
23. Bacq, Z. M., Gosselin, L., Dresse, A., and Renson, J. Inhibition of O-methyltransferase by catechol and sensitization to epinephrine. Science 1959, 130, 453.

24. Axelrod, J., and Laroche, M. J. Inhibitor of $\mathrm{O}$-methylation of epinephrine and norepinephrine in vitro and in vivo. Science 1959, 130, 800.

25. Evarts, E. V., Gillespie, L., Jr., Fleming, T. C., and Sjoerdsma, A. Relative lack of pharmacologic action of 3-methoxy analogue of norepinephrine. Proc. Soc. exp. Biol. (N. Y.) 1958, 98, 74. 